\title{
Endogenous financial literacy, saving and stock market participation
}

\author{
Luca Spataro and Lorenzo Corsini*
}

\begin{abstract}
Recent empirical literature provides evidence that financial literacy, human capital, education, savings and stock market participation are interconnected decisions. However, a consolidated theoretical explanation of such connections is missing. We contribute to this topic by building a framework that includes all these decisions in an encompassing model. We build a two-period model in which individuals acquire education, work and save for retirement; financial literacy reduces the costs of managing risky assets available on the stock market. Our results, besides providing a theoretical foundation for the role and the determinants of the above-mentioned decisions, can also explain several stylized facts on literacy, human capital and stock market participation.
\end{abstract}

Keywords: financial literacy, portfolio decisions, human capital, savingfor-retirement, stock market participation

JEL Classification: D14, D91, G11, J24

\footnotetext{
* Spataro: Dipartimento di Economia e Management, Università di Pisa, Via Ridolfi 10, 56124 Pisa, Italy (luca.spataro@unipi.it); Corsini: Dipartimento di Economia e Management, Università di Pisa, Via Ridolfi 10, 56124 Pisa, Italy (lorenzo.corsini@unipi.it). We are grateful for their useful comments to two anonymous referees, to the participants at the seminar held at the Dipartimento di Economia e Management in Pisa, at the PET 13 Conference held in Lisbon and at 11th workshop on Pension, Insurance and Saving held in Paris. The usual disclaimer applies.
} 


\section{Introduction}

Recent reforms of pension systems in several countries entail a higher degree of responsibility on workers' side. This fact, together with an increasing degree of complexity of individuals' financial decisions, has induced both scholars and policymakers to focus on the determinants and the role of financial decisions, such as saving, stock market participation and financial education.

While quite a large number of empirical studies have shed light on the relevance of financial literacy as a key determinant of crucial life-time decisions such as retirement planning and stock market participation (we review these contributions in section 2; see also Mitchell and Lusardi, 2011 for a full coverage on this subject), the theoretical literature on these issues is rather thin.

Among the few studies that cover theoretical aspects, Jappelli and Padula (2013) develop a model where financial literacy affects the returns of non-stochastic savings. Lusardi et al. (2011) develop a numerically simulated life-cycle model where endogenous financial literacy affects the stochastic returns from saving and where exogenous education determines income. Finally, Corsini and Spataro (2015) develop a theoretical model where individuals' decisions on pension plans are affected by complexity costs embedded in more sophisticated plans and investigate how the acquisition of financial literacy influences pension-saving decisions.

On similar lines, even if not directly tackling financial literacy, some works analyze the impact that the acquisition of information and the time spent on asset management can exert on investment behavior. In particular, Ehrlich et al. (2008) analyze how time spent in acquiring information reduces volatility of risky investments and connect this activity to the level of (non-endogenous) human capital. Ehrlich and Shin (2010) and Ehrlich et al. (2011) further develop this aspect by distinguishing between the role of general human capital and 
the role of "specific" human capital, that is, the component of human capital that is particularly useful for managing risky assets of a given country or context.

In this work we aim at making a step further in the theoretical literature on individual financial decisions by providing a unified framework that encompasses human capital formation, financial education, savings and capital market participation. To the best of our knowledge, this has not been done so far.

In particular, differently from previous literature we focus $i$ ) on the fact that the acquisition of financial literacy is beneficial to individuals for managing risky assets on the stock market and thus for diversifying their savings and ii) on the interaction between financial literacy and education, with the latter being endogenously determined and affecting both lifetime income and the cost to acquire financial literacy. Consequently, within our model, savings, financial literacy, education and investment decisions strictly interact and are endogenously determined.

By doing this, we obtain a relationship between financial literacy, education, income and wealth that, although complex, is in line with several observed facts and also stirs some further empirical questions that are worth being addressed.

The work is organized as follows. In section 2 we sketch some stylized facts on financial literacy acquisition and stock market participation unveiled by recent empirical studies. In section 3 we lay out the model and sections 4 and 5 are devoted to the determinants of stock market participation, financial literacy acquisition and wealth accumulation. The empirical implications of our analysis are provided in Section 6. Concluding remarks end the work. 


\section{Some stylized facts on financial education, saving, human capital and stock market participation}

A number of empirical studies have analyzed the subject of financial literacy, its determinants and its consequences on saving decisions and investment behavior. Usually, in these works financial literacy is measured through surveys that contain questions on the concepts of interest compounding, inflation, purchasing power and risk diversification: on the basis of the number of correct answers a literacy score is computed for each individual.

\subsection{Determinants of financial literacy}

Several works analyze the determinants of literacy: some of them are single-country studies $^{1}$, while others, like Jappelli (2010) and Lusardi and Mitchell (2011a), contain crosscountry analyses. These studies highlight some common patterns in both the determinants and the effects of financial literacy and they indicate that financial literacy:

- is lower among younger and older individuals;

- is lower among female individuals;

- is usually higher for self-employed workers and for individuals working in businessrelated sectors;

- is higher for higher income individuals;

- is higher for individuals with higher mathematical and numeracy skills;

- increases with education (schooling) but the actual relationship can be complex.

\footnotetext{
${ }^{1}$ Analyses from Alessie et al. (2011), Almenberg and Säve-Söderbergh, (2011), Crossan et al. (2011), Bucher-Koenen and Lusardi (2011), Fornero and Monticone (2011), Klapper and Panos (2011), Lusardi and Mitchell (2011b) and Sekita (2011) cover, respectively, Netherlands, Sweden, New Zeland, Germany, Italy, Russia, United States and Japan. Evidence from United States on the effect of financial literacy on planning and wealth accumulation is also contained in Lusardi and Mitchell (2007). Finally, evidence from Italy on the effect of literacy on portfolio diversification is contained in Guiso and Jappelli (2009) while evidence from Sweden on how less-sophisticated investors tend to achieve under-diversification is contained in Anderson (2013).
} 
Among these stylized facts, the evidence on the relationship between education and financial literacy requires some further specifications. First, education and financial literacy appear to be correlated but there is evidence that the field of study is also relevant in explaining how the level of schooling actually affects financial literacy (see Almenberg and Save-Soderbergh, 2011). Moreover, when both education and literacy are used as explicative variables in econometric regressions, they are usually both significant so that literacy appears to have an effect above and beyond education (see Lusardi and Mitchell, 2011a).

Finally, some works have also unveiled that age has a relevant effect on literacy and the relationship has an inverted U-shaped pattern. Empirical analyses found that people in the 3565 age group have higher literacy than those outside this age interval: the actual peak in literacy varies depending on the country under investigation, in some cases it falls in the 3550 age group while sometime in the 51-65 age group (see Alessie et al., 2011; BucherKoenen and Lusardi, 2011; Fornero and Monticone 2011; Lusardi and Mitchell, 2011b).

\subsection{The effects and consequences of financial literacy}

From the empirical works we have mentioned above, some clear-cut empirical results on the effects of financial literacy emerge. In particular, financial literacy:

- affects positively the probability to plan for retirement;

- affects positively, other things being equal, wealth accumulation;

- is positively correlated with the degree of portfolio diversification;

- is positively correlated with stock market participation.

Evidence that financial literacy affects positively, other things being equal, wealth accumulation is also detected in Lusardi et al. (2007), Behrman et al. (2012) and van Rooij et al. (2012) and, in particular, this causal effect persists even after controlling for factors like income, age and education. 


\subsection{Participation in stock markets}

The issue of participation in stock markets has also been the object of specific empirical analyses. As already mentioned in the previous subsection, several works confirm that participation is higher for individuals endowed with higher financial literacy. Moreover, Bertaut and Haliassos (1995), Christiansen et al. (2008) and van Rooij et al. (2011) have highlighted several common features that, even after controlling for the positive effect of financial literacy, explain participation in the stock market. The main evidence on participation is that it:

- increases with income level;

- increases with education level and depends on the field of study;

- increases when stock markets are more attractive;

- decreases with risk aversion;

- is lower for female ${ }^{2}$.

The specific effect of the field of study is addressed by Christiansen et al. (2008), who find that individuals with higher education in economics-related disciplines are, all things considered, more likely to invest in the stock market. As for the role of gender, Powell and Ansic (1997) find that female are less likely to take risks in financial investments. The evidence on the role of the attractiveness of stock markets is contained in the works by Malmendier and Nagel (2011) and Thomas and Spataro (2015), who argue that households observing higher stock returns, even at early adult life, are more likely to participate in stock markets.

\footnotetext{
${ }^{2}$ Among other factors not addressed here, Renneboog and Spaenjers (2012) show that also religious beliefs affect saving attitude and stock market participation.
} 


\subsection{Stylized facts and our theoretical contribution}

All the above stylized facts highlight how financial literacy and education, on one hand, and savings and participation in stock markets, on the other hand, are strictly related, not only because the former variables strongly affect the latter, but also because several factors appear to concurrently play a role in determining all these life-time investment decisions.

In what follows we present a model that aims at encompassing all these issues in a unified framework, thus providing both a possible explanation of the stylized facts listed above and some new testable predictions on the role and determinants of saving behavior, stock market participation and financial literacy acquisition.

\section{A Theoretical Model of Human Capital and Saving}

We imagine an economy populated by individuals that live for two periods: in the first one they make a choice between education and labor supply and between consumption and saving; in the second period, they consume what they have saved.

Within this basic structure, we add three characterizing features: (i) savings can be invested either in a safe or in a risky asset (or both) and the latter can only be bought on the stock market; (ii) the management of complex financial assets is time-consuming and, to reduce the time-cost entailed in this activity, individuals may find it convenient to acquire or increase their level of financial literacy (iii) literacy acquisition is also time-consuming but the share of time needed for this investment decreases with the level of human capital. Points (ii) and (iii) reflect in particular the fact that investing in risky assets requires some knowledge of the mechanism behind stocks (something that is also suggested in Bertaut and Haliassos, 1995) as well as some effort to track asset performance. It follows that individuals may find it convenient to invest some time in obtaining financial education; our assumption is that the knowledge obtained from generic education effectively reduces the amount of time 
needed to acquire financial literacy, although to a different extent dependent on the field of study.

Basically we are assuming that individuals' actions reflect the following timeline: in period 1 they i) choose how much human capital to acquire, ii) work and obtain a given income, iii) choose whether to sustain financial management costs and iv) make consumption and investment decisions. In period 2, they simply consume what they have saved.

As for the very investment decision, we assume that individuals not only choose how much to save but also decide whether and how much to invest in financial education. In fact, the latter investment may help them diversify their savings between two assets (i.e. participating in the stock market). We assume that risky assets provide higher returns although they entail higher volatility and complexity: consequently, since the management cost of risky assets is higher, in this case the investment in financial literacy can be particularly rewarding; on the contrary, we imagine that the cost to manage safe assets is nearly negligible. ${ }^{3}$

\subsection{Basic Definitions}

In this subsection we characterize the structure of the model and define its components.

\subsubsection{Lifetime utility}

Individuals live for two periods (working life and retirement) and their lifetime utility is given by

\footnotetext{
${ }^{3}$ We should mention that financial literacy could also have a direct effect on returns or volatility of assets. In our contribution, although not treating this case explicitly, we allow for similar effects in that we assume that literacy facilitates the managing of assets and, thus, it can increase net returns (i.e. net of management costs) of financial investments. For an example in which financial literacy directly affects the returns of (safe) assets see Jappelli and Padula (2013). For works where the acquisition of information exerts an impact on the volatility of investments see Ehrlich et al. (2008), Ehrlich and Shin (2010) and Ehrlich et al. (2011).
} 


$$
U=-e^{-a c_{1}}-\beta e^{-a c_{2}}
$$

where $c_{1}$ and $c_{2}$ are consumption in period one and two respectively, $a$ is the absolute risk aversion coefficient and $\beta$ measures time preference. The above utility function displays the CARA property and is chosen to obtain closed form solutions: however, as we describe in details in subsection 3.1.4, we also allow for an inverse relationship between the risk coefficient $a$ and total resources to be invested, which is in line with observed facts.

\subsubsection{The time constraint}

According to our set-up, in the first period of life individuals split their time-endowment (normalized to 1 ) between time devoted to general education $\theta$, labor supply $l$ and time spent for financial management $c$. The time constraint is thus:

$$
\theta+l+c=1 .
$$

\subsubsection{Human Capital}

As for the investment in general education ${ }^{4}$, we assume that human capital $(h)$ production function is given by

$$
h=\theta^{1 / x}
$$

\footnotetext{
${ }^{4}$ For the sake of simplicity we do not allow human capital acquisition before the working life: although this assumption does not affect qualitatively our results, it probably increases the optimal time spent in education and, consequently reduces the optimal time spent on the job. As a consequence, if we added pre-working life human capital acquisition, the determinants of stock market participation and financial literacy would not change, although we would probably obtain, other things being equal, more participation on the stock markets and more individuals investing in financial literacy. We thank an anonymous referee for pointing us to the consequences of this assumption.
} 
where $x$ measures the degree of effectiveness of the education process in producing human capital. We assume that $x>1$ so that human capital production has decreasing returns, in line with the empirical evidence (see Blundell et al., 1999; Blundell et al., 2000; Dearden, 1999).

\subsubsection{Income}

The income per time-unit $w$ depends on the amount of human capital acquired through education and on a scale factor $k>1$. The amount of income per time-unit worked is

$$
w=k h .
$$

The working life income $W$ is the product of income per time-unit $w$ and labor supply $l$ :

$$
W=k h l \text {. }
$$

Note that $W$ is an increasing function of $k$.

\subsubsection{Risk aversion}

To make our model more realistic we also allow for an inverse relationship between risk aversion and individual's lifetime resources and therefore we assume that

$$
a=k^{-\alpha}
$$

where $\alpha>0$ is the elasticity of risk aversion with respect to income. ${ }^{5}$ Given the above function, we are assuming that only the exogenous determinant of lifetime resources (that is, the parameter $k$ ) influences risk aversion. We make this assumption to guarantee that human capital does not influence directly risk aversion and to avoid that individuals, when determining their optimal level of human capital and wealth, are also choosing their own degree of risk aversion.

\footnotetext{
5 This methodology of dealing with lifetime resources and decreasing risk aversion has been first proposed by Makarov and Schornick (2010) and can help explain the empirical finding that richer individuals have a preference for riskier assets (see, for example, Vissing-Jorgensen, 2002).
} 
Given eq. (6), an increase in $\alpha$ implies, other things being equal, a decrease in risk aversion. Moreover, relative risk aversion is increasing for $0<\alpha<1$, constant for $\alpha=1$ and decreasing for $\alpha>1$.

\subsubsection{Savings}

Individuals can save through two possible assets. A safe asset yielding a certain rate of return $s$ and a risky asset, available on the stock market, providing a rate of return that is normally distributed with mean $r$ and variance $\sigma^{2}$. We indicate with $S$ the amount invested in the safe asset and with $R$ the amount invested in the risky asset.

\subsubsection{Costs for financial assets management}

Managing financial assets is a complex task and some time is needed to handle and to track stock performance. Consequently, there are some opportunity costs associated with the possibility to invest in assets, which cover the time spent to manage them and to acquire the needed financial knowledge. Given the complexity of stock markets, we can assume that these costs are particularly relevant for individuals that enter the stock market, while they are much smaller or even negligible for individuals that only invest in safe assets.

We assume that the total time-cost of managing financial investments, $c$ (measured in time unit), depends on two components: $q$, related to time spent managing financial assets and $f$, related to time spent investing in financial knowledge, $L$. Moreover, it is likely that the former component is affected by the latter: that is, acquiring financial knowledge strictly reduces the time needed to manage financial assets. Total cost in unit of time thus reads as

$$
c=d(q+f)
$$

where $d \geq 0$ is a parameter that measures the degree of complexity of this activity; clearly, the corresponding opportunity cost is $c \cdot w$. We develop our analysis in such a way that $c$ will 
depend inversely on the stock of human capital of the individual. In particular, it can be shown that when individuals are allowed to optimally choose $q$ and $f$ (and thus acquire financial education $L$ ), eq. (7) reads as (see appendix A for details):

$$
c(h)=d\left(1-h^{1-z}\right)
$$

where the parameter $0<z<1$ is a measure of the effectiveness of human capital (i.e. education) in facilitating the acquisition of financial knowledge. We note that, by this specification, different fields of education have different degrees of complementarity with financial skills and such a degree of closeness of human capital to financial education is in fact captured by the parameter $z$. In other words, the latter parameter measures to what extend human capital is specifically useful in facilitating asset management and in acquiring financial literacy. From this point of view there could be some similarities with the concept of "specific" human capital introduced in Ehrlich and Shin (2010) and Ehrlich et al (2011). However, while in these contributions specific human capital represents the knowledge about a specific country or region, in the present work $z$ captures those skills and knowledge that enhance the acquisition of financial literacy and increase efficiency in managing any asset. ${ }^{6}$

\subsection{The optimization problem}

As for financial investments, individuals must choose whether to enter the stock market and buy risky assets (thus paying also higher costs) or to simply invest in safe assets. In the first case they choose the optimal amount of $h, S$ and $R$, whereas in the second case they simply choose $h$ and $S$. Depending on the complexity of assets, agents might sustain a time-

\footnotetext{
${ }^{6} \mathrm{We}$ recognize that $z$, interpreted as the field of study could, at least in part, be endogenous. However, for the sake of tractability we leave the analysis of this case for future research. As for the present paper, we could also interpret this parameter as the intensity by which the education system of a country or of a region provides economics-related topics in compulsory education, which is exogenous to individuals.
} 
cost: for the sake of simplicity here we assume that the parameter $d$ in eq. (8) is equal to 0 for safe assets and 1 for risky assets.

The optimal amounts chosen under the two alternatives (safe assets only or a combination of risky and safe assets) determine two different indirect expected utilities, one for each investment strategy. By convention, we assume that individuals do not enter the stock market when the two indirect utilities are equal. At the end of this subsection we will be able to show the optimal choice of human capital, consumption and saving in the two cases and the resulting indirect expected utilities.

\subsubsection{Safe assets only}

If an individual does not join the stock market all savings will be invested into the safe asset only. In this case, asset management is rather simple and, given our assumption, no time-cost must be paid for it nor to acquire incremental financial education. The individual time constraint implies then

$$
l=1-\theta=1-h^{x}
$$

and the following budget constraints hold:

$$
\begin{aligned}
& c_{1}=W-S=k h\left(1-h^{x}\right)-S \\
& c_{2}=S(1+s) .
\end{aligned}
$$

Substituting eqs. (10) and (10a) into (1), the individual maximization problem is:

$$
\max _{h, S}-e^{-a\left[k h\left(1-h^{x}\right)-S\right]}-\beta e^{-a[S(1+s)]}
$$

and the solution implies 


$$
\begin{aligned}
& h^{*}=\left(\frac{1}{1+x}\right)^{\frac{1}{x}} \\
& S^{*}=\left[k h^{*}\left(1-\left(h^{*}\right)^{x}\right)+\frac{\log \beta(1+s)}{a}\right] \frac{1}{2+s},
\end{aligned}
$$

where $h^{*}$ and $S^{*}$ are the optimal levels of human capital and saving, respectively (the formal derivation of eqs. (12) and (13) is provided in Appendix B).

The above solutions also provide the following optimal lifetime income $W^{*}$

$$
W^{*}=k h^{*}\left(1-h^{*}\right)=k\left(\frac{x}{1+x}\right)\left(\frac{1}{1+x}\right)^{\frac{1}{x}}
$$

Finally, the associated indirect utility when investing in the safe asset only is:

$$
E U^{*}=-\left(\frac{2+s}{1+s}\right) e^{-a\left(\frac{1}{2+s}\right)\left((1+s) W^{*}-\frac{\log \beta(1+s)}{a}\right)} .
$$

\subsubsection{Safe and risky assets}

An individual choosing to enter the stock market can invest their savings in either the safe or risky asset (or both), but in any case has to pay the time-cost $c$ for asset management and to invest in extra financial education. Given our assumptions, the time constraints is

$$
l=1-\theta-c=h^{1-z}-h^{x}
$$

and the associated budget constraints are:

$$
\begin{aligned}
& c_{1}=W-c(h) w-S-R=k h\left(-h^{x}+h^{1-z}\right)-S-R \\
& c_{2} \sim N\left(S(1+s)+R(1+r), R^{2} \sigma^{2}\right)
\end{aligned}
$$


where $c_{2}$ is now a stochastic variable (in fact, returns from risky asset are stochastic). Given the above equations for consumption, the maximization problem becomes ${ }^{7}$

$$
\max _{h, S, R}-e^{-a\left[k h\left(-h^{x}+h^{1-z}\right)-S-R\right]}-\beta e^{-a\left[S(1+S)+R(1+r)-\frac{a \sigma^{2} R^{2}}{2}\right]} .
$$

The solution of eq. (18) implies

$$
h_{F}^{*}=\left(\frac{2-z}{1+x}\right)^{\frac{1}{x-1+z}}
$$

where $h_{F}^{*}$ is the optimal amount of human capital when the individual decides to invest also in risky assets. Interestingly, by comparing eqs. (12) and (19) it descends that $h_{F}^{*}>h^{*}$ : in fact, given that human capital reduces the cost of asset management, individuals joining the stock market also find it convenient to invest more in education. The above equation also yields the following optimal lifetime income $\left(W_{F}^{*}\right)$ and savings $\left(R_{F}^{*}, S_{F}^{*}\right)$ :

$$
\begin{aligned}
& W_{F}^{*}=k\left(\frac{x-1+z}{2-z}\right)\left(\frac{2-z}{1+x}\right)^{\frac{1+x}{x-1+z}} . \\
& R_{F}^{*}=\frac{r-s}{a \sigma^{2}} \\
& S_{F}^{*}=\left[W_{F}^{*}+\frac{\log \beta(1+s)}{a}-\left(2+\frac{r+s}{2}\right) \frac{r-s}{a \sigma^{2}}\right]\left(\frac{1}{2+s}\right)
\end{aligned}
$$

where $S_{F}^{*}$ and $R_{F}^{*}$ are, respectively, the optimal amount of safe and risky investments (the formal derivation of eqs. (19), (21) and (22) is provided in Appendix B). Finally, the indirect utility in this case is

$$
E U_{F}^{*}=-\frac{2+s}{1+s} e^{-a\left[(1+s) W_{F}^{*}-\frac{\log \beta(1+s)}{a}+\frac{(r-s)^{2}}{2 a \sigma^{2}}\right]\left(\frac{1}{2+s}\right)} .
$$

\footnotetext{
${ }^{7}$ We exploit here a well-known property by which, for any given stochastic variable $n_{j}$ distributed normally with mean $n$ and variance $\sigma_{n}^{2}$, we have that $E\left(e^{-a n_{j}}\right)=e^{-a\left(n-a \sigma_{n}^{2} / 2\right)}$ : see Varian (1992).
} 


\subsection{Participation in the stock market and acquisition of financial literacy}

As already mentioned, individuals choose to enter the stock market when the resulting indirect utility is higher than the one obtaining in the alternative strategy. In terms of our model this happens if $E U_{F}^{*}>E U^{*}$, that is, given eqs. (15) and (23), if

$$
-\left(\frac{2+s}{1+s}\right) e^{-a\left[(1+s) W_{F}^{*}-\frac{\log \beta(1+s)}{a}+\frac{(r-s)^{2}}{2 a \sigma^{2}}\right]\left(\frac{1}{2+s}\right)}>-\left(\frac{2+s}{1+s}\right) e^{-a\left(\frac{1}{2+s}\right)\left[(1+s) W^{*}-\frac{\log \beta(1+s)}{a}\right]}
$$

which implies

$$
W^{*}-W_{F}^{*}<\frac{1}{1+s} \frac{(r-s)^{2}}{2 a \sigma^{2}}
$$

Exploiting eqs. (6), (14) and (20), inequality (24a) reads as:

$$
\left(\frac{x}{1+x}\right)\left(\frac{1}{1+x}\right)^{\frac{1}{x}}-\left(\frac{x-1+z}{2-z}\right)\left(\frac{2-z}{1+x}\right)^{\frac{1+x}{x-1+z}}<\frac{1}{k^{1-\alpha}}\left[\frac{1}{1+s} \frac{(r-s)^{2}}{2 \sigma^{2}}\right]
$$

The above inequality determines univocally whether individuals invest in the stock market and acquire financial literacy or not.

The left hand side of inequality (24b) is a decreasing function of $x$ and $z$ (the proof is contained in Appendix C): thus, individuals whose education investment is more effective in producing human capital (i.e. higher $x$ ) or in abating portfolio management costs (i.e. higher z) are more likely to participate in the stock market and to acquire financial education.

The right hand side of inequality (24b) is increasing in the risk premium $(r-s)$ and decreasing in the degree of risk aversion (in fact, the RHS is increasing in $\alpha$ ), the variance of risky asset returns and the return from the safe asset, which implies that individuals are more likely to invest in risky assets and acquire financial literacy when the excess return of the risky asset is high, when its volatility is low and when their risk aversion is low. The RHS also depends on lifetime income, as the latter influences both risk aversion and the 
opportunity costs of risky assets management. However, these effects are only due to the component $k$ of lifetime resources and the sign of the total effect depends on the value of $\alpha$ : for $\alpha<1$ the component $k$ has a negative effect on the RHS, for $\alpha>1$ it has a positive effect and for $\alpha=1$ it has no effect. Accordingly, for a given level of human capital, richer individuals are more/less likely to enter the stock market and acquire financial literacy depending on whether the value of the elasticity of risk aversion with respect to lifetime income is larger/lower than 1 , respectively.

For illustrative purposes in Figure 1 we present a graphic representation of inequality (24b), where $G \equiv \frac{1}{k^{1-\alpha}}\left[\frac{1}{1+s} \frac{(r-s)^{2}}{2 \sigma^{2}}\right]$ is the RHS and the two decreasing curves represent the LHS, that is the difference between $W^{*}-W_{F}^{*}$, as a function of $x$, for two distinct values of $z$ $(z=0.8$ and $z=0.9$ for the higher and lower curve respectively). For values of the curve below the $G$ line individuals enter the stock market and invest in financial education. As it is clear from the decreasing pattern of the curves, only individuals with a value of $x$ higher than a certain threshold $x^{*}$ actually invest in risky assets management. Moreover, an increase in the value of $z$ shifts the curve downward so that the threshold value of $x$ becomes smaller.

Figure 1: Threshold levels of $x$ determining the incentives to invest in stock market and financial literacy, for different levels of $\mathrm{z}$. 


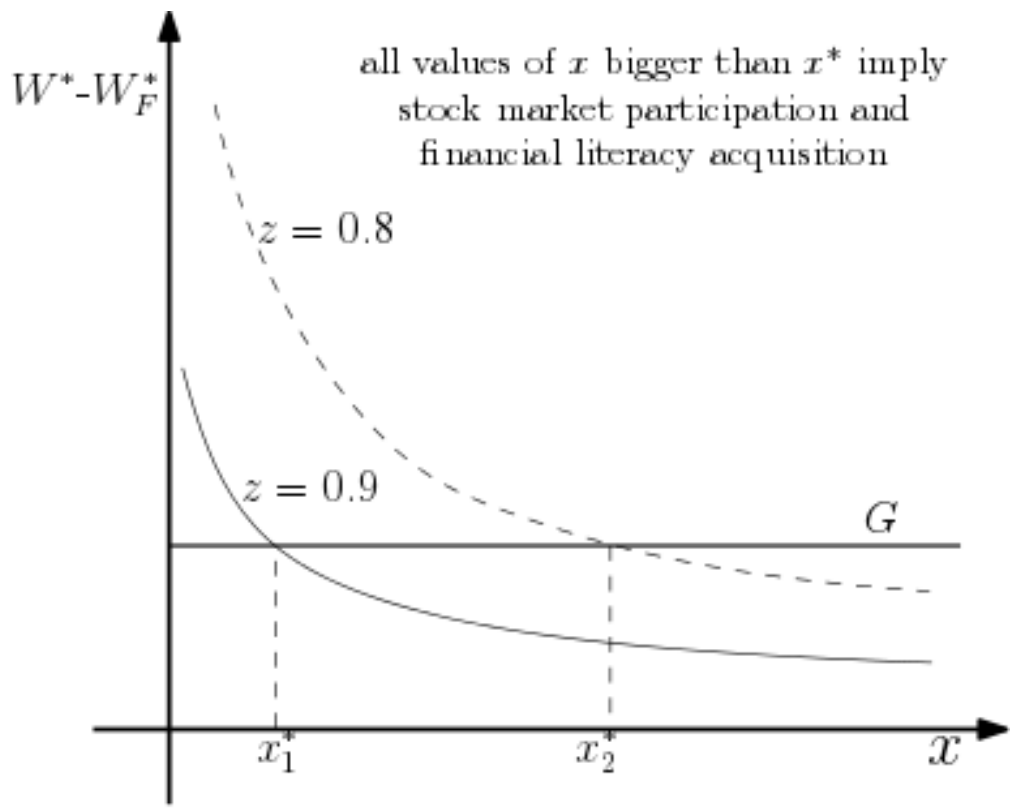

Finally, our model also determines the optimal amount of literacy that individuals acquire to abate the management costs of risky assets. This optimal amount is obtained through the optimization process on time allocation that delivered eq. (8) and is equal to (see appendix A):

$$
L^{*}=\left(\frac{2-z}{1+x}\right)^{\frac{1-z}{x-1+z}}
$$

\section{The determinants of financial literacy and of stock market participation}

In the light of the analysis carried out so far, we can summarize our findings through several propositions. The following two propositions stem from inequality (24b).

Proposition 1. The share of individuals that acquire financial literacy and participate to the stock market is an increasing function of the excess return of risky assets ( $r-s)$ and a decreasing function of the rate of return of the safe asset $s$ and of the variance of risky asset returns $\left(\sigma^{2}\right)$.

Proof. The proof follows by inspection of the RHS of inequality (24b). 
Quite obviously, the share of individuals participating in the stock market increases when the risky asset becomes more attractive in terms of mean returns and volatility. In addition, an increase of the return of safe asset (keeping the risk premium constant) reduces participation. This is due to the fact that when $s$ increases the overall wealth increases as well and this magnifies the difference between $W^{*}$ and $W_{F}^{*}$ (as the former is strictly larger than the latter).

By exploiting the LHS of inequality (24), we can write the following:

Proposition 2. Individuals bestowed with larger values of $x$ and $z$ are more likely to acquire financial literacy and to participate in the stock market.

Proof. See Appendix C.

We can provide an economic interpretation of the content of Proposition 2. In fact, the parameter $x$ measures how effective individuals are in acquiring education and human capital (or how effective the education system is in providing individuals with human capital). Hence, individuals with larger values of $x$, ceteris paribus, acquire more human capital and, as a side effect of human capital and education, sustain lower costs for asset management and financial literacy acquisition. Consequently, these individuals are more likely to enter the stock market and acquire literacy. As for parameter $z$, it measures how effective human capital and education are in abating the financial management costs: individuals with higher value of $z$ have trained in education activities that are closer to finance and their costs to manage risky assets and to acquire financial literacy are smaller.

Finally, we can also provide the following Proposition on the optimal amount of financial literacy:

Proposition 3. The amount of financial literacy acquired is larger for individuals bestowed with larger $x$ and larger $z$. 
Proof. See Appendix C.

This result reflects two relevant economic mechanisms: first, when the acquisition of human capital is more effective (higher $x$ ) individuals end up having larger human capital and this makes it easier to acquire literacy; second, a human capital that is closer to the financial sector (higher $z$ ) further reduces the cost of acquiring literacy and this provides incentives to invest in it. This result also implies that the level of financial literacy, for individuals of a given degree of education, varies depending on $z$ : that is, individuals with the same years of schooling could have acquired different levels of financial literacy, depending on their actual field of study.

\section{Savings and Wealth accumulation}

In this section we explore the role that individuals' financial investment strategy has in determining wealth accumulation.

For the sake of simplicity, we define wealth as the total amount that has been accumulated during the working-life, net of capitalization of interests: at the end of the section we will discuss how the results are even more robust if we also include the capitalization of interests.

We compute first the total amounts saved by individuals who invested in safe assets and did not invested in the stock market. In particular, if an individual does not invest in risky assets the resulting total lifetime savings are equal to the amount invested in the safe asset:

$$
S^{*}=\left[W^{*}+\frac{\log \beta(1+s)}{a}\right] \frac{1}{2+s} .
$$

On the contrary, if an individual enters the stock market, total savings are given by the sum of the amounts invested both in the safe and in the risky asset: 


$$
S_{F}^{*}+R_{F}^{*}=\left[W_{F}^{*}+\frac{\log \beta(1+s)}{a}\right] \frac{1}{2+s}+\left(1-\frac{r-s}{2} \frac{1}{2+s}\right) \frac{r-s}{2 a \sigma^{2}} .
$$

Given the above results we can evaluate whether joining the stock market and acquiring financial literacy implies higher wealth accumulation. Suppose then that we observe two different individuals: agent 1 has entered the stock market while agent 2 has not, either because they have different preferences (identified by different values of $\beta$ and $a$ ) or different values of any of the triplet $(x, z, k)$. The difference in their total savings is given by the following (the subscript identifies the agent):

$$
S_{F, 1}^{*}+R_{F, 1}^{*}-S_{2}=\left[W_{F, 1}^{*}-W_{2}^{*}+\frac{\log \beta_{1}(1+s)}{a_{1}}-\frac{\log \beta_{2}(1+s)}{a_{2}}\right] \frac{1}{2+s}+\left(1-\frac{r-s}{2} \frac{1}{2+s}\right) \frac{r-s}{2 a_{1} \sigma^{2}}
$$

We can exploit the above equation to formulate the following proposition:

Proposition 4. Suppose that two individuals are identical in terms of lifetime income $(W)$, risk aversion (a) and time preference $(\beta)$ but they differ in that the former has entered the stock market and acquired financial literacy and the latter has not. Then, if $r<4+3 s$, the former individual accumulates also a larger amount of wealth.

Proof. If individuals are identical in terms of their lifetime income, risk aversion and time preferences we have, by assumption, $W_{F, 1}^{*}-W_{2}^{*}=0$ (by eqs. (14) and (20) and, given a triplet $\left(x_{1}, z_{1}, k_{1}\right)$, we can always find a combination of $x_{2}, z_{2}$ and $k_{2}$ providing such an equality), $a_{1}=a_{2}$ and $\beta_{1}=\beta_{2}$ and, consequently, from eq. (28) we have $S_{F, 1}^{*}+R_{F, 1}^{*}-S_{2}=$ $\left(1-\frac{r-s}{2} \frac{1}{2+s}\right) \frac{r-s}{2 a_{1} \sigma^{2}}$. The latter is strictly positive for $r<4+3 s$.

Condition $r<4+3 s$ is satisfied for realistic values of the parameters, so that our results imply that individuals that have invested in the stock market and acquired financial literacy 
accumulate a higher amount of wealth ${ }^{8}$ relative to individuals who have the same preferences and life-time income but did not invested in stock markets nor in financial literacy.

In our definition of wealth we did not include the capitalization of returns: if we had also included this factor, given that $E(r)>s$, it is easy to see that the wealth of individuals investing in the stock market and financial literacy would be, on average, larger than the amount accumulated by the others, for an even less stringent condition than $r<4+3 s$. That is, engaging in risky assets management would imply, on average, an even larger accumulation of wealth.

\section{Main Findings and Reconciling Theory with Evidence}

The model we have presented delivers some clear-cut results on the determinants of financial literacy acquisition and stock market participation. In this section we compare our theoretical findings with the stylized facts presented in section 2 and we also provide some further empirical insights.

\subsection{Education and numeracy}

According to our results, there is a positive relationship between education and financial literacy. However, the degree of education and financial literacy are not perfectly correlated: in fact, the field of study (possibly represented by the parameter $z$ in our model) is

\footnotetext{
${ }^{8}$ Assuming that a period is 30 years long, a sufficient (but not necessary) condition for the inequality $r<4+3 s$ to be satisfied is that the excess return does not exceed $4 \%$. Therefore, only for extremely high excess return the conclusion could be reverted: this theoretical occurrence is due to income effect that, when $r$ is extremely high relative to $s$, induces individuals that are investing in the stock market to consume more in both periods, thus reducing the amount they are saving. A numerical exercise can clarify this point: in the last 50 years, in US the geometric averages of the real returns from the stock market and from the Treasury Bills were 5.3\% and $0.08 \%$, respectively (see Board of Governors of the Federal Reserve System US, 2016 and Crawford et al., 2016). If we use these data to compute $r$ and $s$ over a horizon of 30 years we obtain that $r$ is 3.7 and $s$ is 0.27 : these values satisfy the inequality of Proposition 4. Given that Treasury Bills returns should be considered the lower bound for safe asset returns, the inequality of Proposition 4 appears to be satisfied for historical US data of the last 50 years. We thank an anonymous referee for pointing us to such an empirical check.
} 
also a key determinant. This is in line with the observed facts (see subsection 2.1) whereby, on the one hand, schooling exerts a positive effect on financial knowledge (although with a wide variability which depends, among other things, on the field of study) and, on the other hand, literacy has an effect that goes beyond mere education level. Our model also indicates that education systems that are more effective in providing human capital (i.e. higher $x$ ) not only improve human capital accumulation, but also capital market participation and financial literacy acquirement. As an empirically testable result, we predict that for a given level of schooling, financial literacy should vary across individuals depending on the field of study and on the efficiency of education system (at cohort, regional or country level) in producing human capital.

Moreover, individuals that have developed good abilities in math and numeracy can be thought as having, according to our model, a higher level of $z$ and thus, should be more likely to acquire financial literacy and invest in stock markets, which is line with the observed evidence (see subsection 2.1).

\subsection{Income}

Our results provide a complex relationship between income and literacy, which can be broken down into three components. First, both income and literacy are positively influenced by education: this component implies a positive correlation but not a causal relationship between income and literacy. Second, higher income implies higher amount of lifetime resources to be invested and also lower risk aversion. This in turn implies that individuals with higher income are keen to buy a higher amount of stocks and, consequently, of financial literacy in order to enter the stock market: therefore, this component entails a causal positive relationship between income and literacy. Finally, higher income also implies higher 
opportunity costs and this produces a negative effect of income on the incentives to acquire financial literacy. Our model allows us to determine the overall effect of the latter two components and in particular we have that for $\alpha \geq 1$ (that is, when relative risk aversion is non-increasing in income) the overall effect is non-negative whereas it is negative otherwise. As a consequence, if we consider all the three components we can be certain that for $\alpha \geq 1$ income and literacy (and stock market participation) are positively correlated whereas for $\alpha<1$ the sign of the relationship is undetermined. The assumption that relative risk aversion is non-increasing in income is usually the most realistic one (see, for example, MasColell et al., 1995, chapter 6) and thus, our model fully explains the observed positive correlation between income and financial literacy (discussed in subsection in 2.1) and between income and stock market participation (discussed in subsection in 2.3). Further empirical analysis aimed at disentangling the role of income from that of education would however be helpful to shed further light on the ultimate nature of the relationship between these two factors.

\subsection{Employment condition}

Individuals employed in sectors close to business are likely to have acquired a type of human capital which displays higher complementarities with financial knowledge. In analytical terms of our model, this implies higher $z$ and thus, these individuals should be more likely to acquire financial literacy and join the stock market. A similar reasoning can be used for self-employed workers: in fact, it is likely that, on the one hand, the education that self-employed acquired to perform their work and, on the other hand, the experience they have gained on the job entails a certain degree of complementarity with financial education. In terms of our model, this translates into higher z. Moreover, given the entrepreneurial nature of self-employment, they should probably have lower risk aversion (higher $\alpha$ in our 
model). According to these lines of reasoning our model predicts that self-employed have higher probability of acquiring literacy and investing in risky assets. These theoretical predictions are in line with the observed evidence described in subsection 2.1 and 2.3.

\subsection{Gender}

Our model does not include any gender differences and as such, cannot account for gender gaps. However, we find that higher risk aversion reduces the incentive to acquire financial literacy and invest in stocks. Given that there exists some evidence that females have higher risk aversion (see Borghans et al., 2009; Croson and Gneezy, 2009), this could explain, at least to some extent, the observed gender differences in financial literacy and stock market participation that we discussed in subsections 2.1 and 2.3. However, Barber et al. (2001) show that risk aversion alone is not always enough to explain gender differences in investment behavior: therefore, further empirical analyses are in any case needed to discern whether risk aversion, ceteris paribus, fully explains the gender gap in financial literacy or not.

\subsection{Wealth}

Our analysis shows that, for realistic values of the parameters, individuals who have acquired financial literacy and have invested in stocks tend to accumulate larger amounts of wealth. This result, which is in line with the empirical evidence discussed in subsection 2.2, is due to the fact that these individuals save larger amounts and is even truer if the stock market grants returns that are, on average, higher. A testable implication of our model is that individuals with larger financial literacy have, ceteris paribus, larger propensity to save.

\subsection{Stock market participation}

Our model strongly relates the participation in stock markets to the acquisition of financial literacy. As such, education and income, influencing literacy, also increase the 
likelihood to acquire stocks, something that has been observed in reality. Moreover, we highlight how schooling attainment alone is not enough to explain participation, given that the field of study plays a relevant role too. Finally, and somehow obviously, higher risk aversion reduces the likelihood to acquire stocks. All these theoretical results are in line with the empirical evidence on the relationship between financial literacy and stock market participation (see subsection 2.1) and on the other determinants of participation (see subsection 2.3).

\subsection{The attractiveness of risky assets}

We find that the more attractive (in terms of Sharpe-ratios) the risky assets, the larger the incentives to acquire financial literacy and to invest in stocks. The latter result is in line with evidence described in subsection 2.3. The similar prediction on financial literacy acquisition has not been tested so far and it would be interesting to test it in terms of differences at cohort and/or cross-country level.

\section{Conclusions}

In the present work we have built a model that encompasses in a unified framework human capital investment, financial literacy acquirement, saving behavior and participation in the stock market. Our model provides a clear account of the effects that education, field of study, income and employment conditions have on financial literacy and stock market participation. In addition, even if we do not address it directly, the observed effect of gender on financial decisions can find a partial rationale within our framework in terms of differences in risk aversion. Some of our theoretical results stimulate further empirical analysis: a first empirical implication is that individuals or countries with education systems that perform better in producing human capital should also have higher levels of financial literacy and higher participation in stock markets. A second implication is that individuals 
living in countries with education systems that provide basic financial education should display higher participation rates in the stock market, higher financial literacy and higher propensity to save. Finally, our findings put an emphasis on the role of other institutional factors, such as gender wage-gap or more attractive capital markets, as possible determinants of differences in financial literacy attainment or stock market participation, both at cohort and country level. All these empirical implications are left for future empirical research. Another interesting avenue for future research is the possible extension of the present analysis to a multi-period framework, in such a way that the role of age and family composition, both documented by the empirical literature and disregarded here, could be assessed.

Finally, the results of our model offer some relevant policy implications. Given the increasing importance of private savings in determining individuals' economic well-being in current and future societies, the adequacy of households' saving is an issue of major concern. Our model predicts that saving behavior (and the propensity to save) depends on financial literacy, which in turn depends, among other things, on education. Therefore, our findings suggest that policies aimed at fostering general education and economics-related knowledge are highly beneficial both for increasing financial literacy and for promoting economic wellbeing of individuals through higher saving and portfolio diversification.

Indeed, the interaction between education and financial literacy is at the center of the current political debate of many countries: the Programme for International Student Assessment (PISA), for example, has recently added specific modules to measure and evaluate the financial literacy skills of young students (see OECD, 2014) and several OECD countries are discussing how to promote financial education (see OECD, 2016). However, only few of them (UK is one of the rare examples, see OECD, 2016) actually implemented compulsory financial education curricula within their general education systems. Our analysis 
provides solid arguments in support of these policies and calls for an enhancement at the international level.

\section{APPENDIX A - Micro-foundation of asset management costs and direct acquisition of financial literacy}

We provide here the micro-foundation of asset management costs (eq. (8) in the text). The basic idea we develop here is that investing in risky assets is a complex activity and requires time to evaluate, choose and keep track of assets performance. Given this complexity, it is sensible to expect that the time spent in this process depends inversely on the level of financial literacy of individuals. Therefore, individuals choosing to invest in risky assets may find it convenient to invest also part of their time not only in general education but also in financial education: in fact, this investment will allow them to acquire financial literacy and, thus, to abate the time spent in participating in financial markets.

Hence, we assume that the time-cost entailed in financial management is made of two components: $q$ and $f$ (see eq. 7). The former is associated with time spent to evaluate, choose and track the risky assets performance, which is assumed to depend inversely on the level of financial literacy $L$, that is:

$$
q=1-2 L
$$

The latter component $f$ is related to the time spent acquiring financial education $L$ according to the following production function:

$$
L=\left(f h^{1-z}\right)^{1 / 2}
$$

The output $L$ is increasing in $f$ and its marginal productivity depends positively on the level of general education of individuals $(h)$ and on how useful the specific education is in the 
acquisition of literacy (e.g. the field of study, measured by z). Finally, we assume that the marginal productivity of $f$ is decreasing. By exploiting eqs (7), (A1) and (A2), we get:

$$
c(L, h)=d(q+f)=d\left(1-2 L+L^{2} h^{z-1}\right) .
$$

By plugging eq. (A3) and the equations for the budget constraint (17) and (17b) into (1), the maximization problem reads as:

$$
\max _{h, L, S, R}-e^{-a\left[k h\left(1-h^{x}-d+2 d L-d L^{2} h^{z-1}\right)-S-R\right]}-\beta e^{-a\left[S(1+S)+R(1+r)-\frac{a \sigma^{2} R^{2}}{2}\right]} .
$$

The solution of (A4) with respect to $L$ yields

$$
\frac{\partial E U_{R}}{\partial L}=0 \Rightarrow-a k h d\left(2-2 L h^{z-1}\right) e^{-a\left[k h\left(1-h^{x}-d+2 d L-d L^{2} h^{z-1}\right)-S-R\right]}=0 .
$$

So that:

$$
L^{*}=h^{1-z}
$$

which, together with eq. (A3), implies:

$$
c\left(L^{*}, h\right)=d\left(1-h^{1-z}\right)
$$

which is eq. (8) in the text. Moreover, eqs. (A6) and (19) determine the optimal level of financial literacy acquired by individuals:

$$
L^{*}=\left(\frac{2-z}{1+x}\right)^{\frac{1-z}{x-1+z}}
$$




\section{APPENDIX B - Optimal levels of human capital and investment in safe and risky assets}

We derive here the optimal levels $h^{*}$ and $S^{*}$ as given, respectively, by eqs. (12) and (13) and the optimal levels $h_{F}^{*}, R_{F}^{*}$ and $S_{F}^{*}$ as given, respectively, by eqs. (19), (20) and (21).

\section{B.1. Derivation of $h^{*}$ and $S^{*}$}

Consider the optimization problem $\max _{h, S}-e^{-a\left[k h\left(1-h^{x}\right)-S\right]}-\beta e^{-a[S(1+s)]}$. The first order conditions imply

$$
\begin{aligned}
& \frac{\partial\left\{-e^{-a\left[k h\left(1-h^{x}\right)-S\right]}-\beta e^{-a[S(1+s)]}\right\}}{\partial h}=0 \Rightarrow a k h\left[1-(1+x) h^{x}\right] e^{-a\left[k h\left(1-h^{x}\right)-S\right]}=0 \\
& \frac{\partial\left\{-e^{-a\left[k h\left(1-h^{x}\right)-S\right]}-\beta e^{-a[S(1+s)]}\right\}}{\partial S}=0 \Rightarrow a e^{-a\left[k h\left(1-h^{x}\right)-S\right]}-a \beta(1+s) e^{-a[S(1+s)]}=0 .
\end{aligned}
$$

From (B1) we directly obtain the optimal level of human capital $h^{*}$ :

$$
h^{*}=\left(\frac{1}{1+x}\right)^{\frac{1}{x}}
$$

and from (B2), inserting $h^{*}$, we obtain the optimal level of saving $S^{*}$ :

$$
S^{*}=\left[k h^{*}\left(1-h^{* x}\right)+\frac{\log \beta(1+s)}{a}\right] \frac{1}{2+s} .
$$

\section{B.2 Derivation of $h_{F}^{*}, R_{F}^{*}$ and $S_{F}^{*}$}

Consider the optimization problem

$$
\max _{h, S, R}-e^{-a\left[k h\left(-h^{x}+h^{1-z}\right)-S-R\right]}-\beta e^{-a\left[S(1+s)+R(1+r)-\frac{a \sigma^{2} R^{2}}{2}\right]} .
$$

The first order conditions imply 


$$
\frac{\partial\left\{-e^{-a\left[k h\left(h^{1-z}-h^{x}\right)-S-R\right]}-\beta e^{-a\left[S(1+s)+R(1+r)-\frac{a \sigma^{2} R^{2}}{2}\right]}\right\}}{\partial h}=0 \Rightarrow
$$

$$
\begin{array}{r}
a k\left[(2-z) h^{1-z}-(1+x) h^{x}\right] e^{-a\left[k h\left(h^{1-z}-h^{x}\right)-S-R\right]}=0 ; \\
\frac{\partial\left\{-e^{-a\left[k h\left(-h^{x}+h^{1-z}\right)-S-R\right]}-\beta e^{-a\left[S(1+s)+R(1+r)-\frac{a \sigma^{2} R^{2}}{2}\right]}\right\}}{\partial S}=0 \Rightarrow
\end{array}
$$

$$
\begin{gathered}
a e^{-a\left[k h\left(-h^{x}+h^{1-z}\right)-S-R\right]}=a \beta(1+s) e^{-a\left[S(1+s)+R(1+r)-\frac{a \sigma^{2} R^{2}}{2}\right]} ; \\
\frac{\partial\left\{-e^{-a\left[k h\left(-h^{x}+h^{1-z}\right)-S-R\right]}-\beta e^{-a\left[S(1+s)+R(1+r)-\frac{a \sigma^{2} R^{2}}{2}\right]}\right\}}{\partial R}=0 \Rightarrow \\
a e^{-a\left[k h\left(-h^{x}+h^{1-z}\right)-S-R\right]}=a \beta\left[(1+r)-a \sigma^{2} R\right] e^{-a\left[S(1+s)+R(1+r)-\frac{a \sigma^{2} R^{2}}{2}\right]} .
\end{gathered}
$$

From eq. (B5) we directly obtain the optimal level of human capital $h_{F}^{*}$ :

$$
h_{F}^{*}=\left(\frac{2-z}{1+x}\right)^{\frac{1}{x-1+z}}
$$

Moreover, combining eqs. (B6)-(B8) we obtain the optimal level of investment in risky assets $R_{F}^{*}$ and the optimal level of investment in safe assets $S_{F}^{*}$ :

$$
\begin{aligned}
& R_{F}^{*}=\frac{r-s}{a \sigma^{2}} \\
& S_{F}^{*}=\left[W_{F}^{*}+\frac{\log \beta(1+s)}{a}-\left(2+\frac{r+s}{2}\right) \frac{r-s}{a \sigma^{2}}\right]\left(\frac{1}{2+s}\right) .
\end{aligned}
$$




\section{APPENDIX C - Proof of Proposition 2 and Proposition 3}

\section{C.1. Proof of Proposition 2}

We prove here Proposition 2. From inequality (24a) we know that individuals acquire financial literacy and enter the stock market if $W^{*}-W_{F}^{*}$ is lower than $\frac{1}{1+s} \frac{(r-s)^{2}}{2 a \sigma^{2}}$. Here we prove that $W^{*}-W_{F}^{*}$ is a decreasing function of $x$ and $z$ and, therefore, individuals with higher $x$ or $z$ are more likely to acquire financial literacy and enter the stock market.

Formally, we need to prove that

$$
\begin{aligned}
& \frac{\partial\left(W^{*}-W_{F}^{*}\right)}{\partial x}<0 \\
& \frac{\partial\left(W^{*}-W_{F}^{*}\right)}{\partial z}<0 .
\end{aligned}
$$

Preliminarily, we define the following variables and functions:

$$
\begin{aligned}
& g \equiv \frac{1}{1+x} \\
& p \equiv \frac{2-z}{1+x} \\
& b(y)=\ln y+1-y \\
& f(y)=y^{\frac{y}{1-y}} \\
& h(y)=f(y)^{f(y)} .
\end{aligned}
$$

Note that by definition, we have that $0<g<p<1$ and that, for $y>0, f(y)>0$ and $h(y)>0$.

Starting from eq. (14) and given definition (C3) we have 


$$
W^{*}=k\left(1-\frac{1}{1+x}\right)\left(\frac{1}{1+x}\right)^{\frac{1}{x}}=k(1-g)(g)^{\frac{g}{1-g}}
$$

Similarly, starting from eq. (20) and given definition (C3) and (C4) we have

$$
W_{F}^{*}=k\left(1-\frac{2-z}{1+x}\right)\left(\frac{2-z}{1+x}\right)^{\frac{2-z}{x-1+z}}=k(1-p)(p)^{\frac{p}{1-p}}
$$

We now present four lemmas and we use them to prove eqs. (C1) and (C2).

Lemma 1 The following properties hold true: $y>0 \Rightarrow b(y) \leq 0$ and $y>0 \cap y \neq 1 \Rightarrow$ $b(y)<0$.

Proof. Starting from definition (C5), we have that $\frac{\partial b(y)}{\partial y}=\frac{\partial(\ln y+1-y)}{\partial y}=\frac{1}{y}-1$. Therefore $\frac{\partial[b(y)]}{\partial y}$ is positive for $y<1$, zero for $y=1$ and negative for $y>1$. It follows that $b(y)$ has a global maximum for $y=1$. We have then that $\max _{y} b(y)=b(1)=0$ which implies that $b(y) \leq 0$. Moreover, given that $b(y)$ is zero only for $y=1$, we also have that $b(y)<0 \forall y>0 \cap y \neq$ 1.

Lemma 2. The following property holds true: $y>0 \cap y \neq 1 \Rightarrow \frac{\partial f(y)}{\partial y}<0$.

Proof. From definitions (C5) and (C6) we compute $\frac{\partial f(y)}{\partial y}=\frac{\frac{y}{y^{1-y}}(\ln y+1-y)}{(y-1)^{2}}=\frac{y^{\frac{y}{1-y}} b(y)}{(y-1)^{2}}$. From Lemma 1 we know that $b(y)>0 \forall y>0 \cap y \neq 1$, thus: $\frac{\partial f(y)}{\partial y}<0 \forall y>0 \cap y \neq 1$.

Lemma 3. The following property holds true: $1 / e<f(p)<f(g)$.

Proof. Given that $0<g<p<1$, from Lemma 2 we necessarily have $f(p)<f(g)$. Moreover, given Lemma 2, the infimum of $f(p)$ is obtained for the supremum of $p$, which, given the definition of $p$, is obtained for $z=0$ and $x \rightarrow 1$. Therefore, $\inf f(p)=\lim _{x \rightarrow 1}\left(\frac{2}{1+x}\right)^{\frac{1+x}{x-1}}$. 
We prove now that $\lim _{x \rightarrow 1}\left(\frac{2}{1+x}\right)^{\frac{1+x}{x-1}}=1 / e$. We define $v \equiv \frac{1-x}{1+x}$ and rearranging $\lim _{x \rightarrow 1}\left(\frac{2}{1+x}\right)^{\frac{1+x}{x-1}}$ we obtain $\lim _{v \rightarrow 0}\left[\left(1+\frac{1}{v}\right)^{\frac{1}{v}}\right]^{-1}$ that, by definition, is equal to $1 / e$. We then have $1 / e<f(p)<$ $f(g)$

Lemma 4. The following property holds true: $0<y \leq p \Rightarrow \frac{\partial h(y)}{\partial y}<0$.

Proof. From definitions (C5), (C6) and (C7) we compute $\frac{\partial h(y)}{\partial y}=\frac{h(y) \frac{\partial f(y)}{\partial y}[1+\ln f(y)]}{y}$. For $0<$ $y \leq p$ we know: $i$ ) by definition, that $y>0$ and $h(y)>0$ are positive; ii) from Lemma 2 , that $\frac{\partial f(y)}{\partial y}<0$; and iii) from Lemma 3 , that $[1+\ln f(y)]>0$. Therefore we necessarily have that, for $0<y \leq p, \frac{\partial h(y)}{\partial y}<0$

We use now the four lemmas to prove (C1) and (C2).

Proof of C1. We can rearrange $\frac{\partial\left(W^{*}-W_{F}^{*}\right)}{\partial x}$ as $\frac{\partial\left(W^{*}-W_{F}^{*}\right)}{\partial x}=\left(\frac{\partial W^{*}}{\partial g} \frac{\partial g}{\partial x}-\frac{\partial W_{F}^{*}}{\partial p} \frac{\partial p}{\partial x}\right)$. From the latter, using definition (C3) and (C4) and eqs. (C8) and (C9), we obtain $\frac{\partial\left(W^{*}-W_{F}^{*}\right)}{\partial x}=$ $-k g\left(g^{\frac{g}{1-g}} \ln g^{\frac{g}{1-g}}-p^{\frac{p}{1-p}} \ln p^{\frac{p}{1-p}}\right)$ and, from definitions (C6) and (C7), we obtain $\frac{\partial\left(W^{*}-W_{F}^{*}\right)}{\partial x}=-k g\left[\ln f(g)^{f(g)}-\ln f(p)^{f(p)}\right]=-k g[\ln h(g)-\ln h(p)] . \quad$ Consider $\quad$ now $[\ln h(g)-\ln h(p)]:$ we know from Lemma 4 that $0<y \leq p \Rightarrow \frac{\partial h(y)}{\partial y}<0$ and, given that $g<p$, it follows that $h(g)>h(p)$ and $[\ln h(g)-\ln h(p)]>0$. Then $\frac{\partial\left(W^{*}-W_{F}^{*}\right)}{\partial x}=$ $-k g[\ln h(g)-\ln h(p)]<0$ 
Proof of C2. We can rearrange $\frac{\partial\left(W^{*}-W_{F}^{*}\right)}{\partial z}$ as $\frac{\partial\left(W^{*}-W_{F}^{*}\right)}{\partial z}=\left(\frac{\partial W^{*}}{\partial g} \frac{\partial g}{\partial z}-\frac{\partial W_{F}^{*}}{\partial p} \frac{\partial p}{\partial z}\right)$. From the latter, given that $\frac{\partial g}{\partial z}=0$ and given eq. (C9), we obtain $\frac{\partial\left(W^{*}-W_{F}^{*}\right)}{\partial z}=-k \frac{p^{\frac{p}{1-p}}}{1-p} \frac{\partial p}{\partial z} \ln p$. From definition (C4) we have that $\frac{\partial p}{\partial z}=-g<0$ and, since $0<p<1$, we have that $-k \frac{p^{\frac{p}{1-p}}}{1-p} \frac{\partial p}{\partial z} \ln p<0$.

\section{C.2. Proof of Proposition 3}

We prove here Proposition 3. Formally, we need to prove that

$$
\begin{gathered}
\frac{\partial L^{*}}{\partial x}>0 \\
\frac{\partial L^{*}}{\partial z}>0
\end{gathered}
$$

where $L^{*}=\left(\frac{2-z}{1+x}\right)^{\frac{1-z}{x-1+z}}$. In what follows we define $q \equiv\left(\frac{2-z}{1+x}\right)^{\frac{1}{x-1+z}}$ and we use the previous definitions $p \equiv \frac{2-z}{1+x}$ and $b(y)=\ln y+1-y$. Note that, by definition, $0<q<1$ and moreover: $q=p^{\frac{1}{(x+1)(1-p)}}, \frac{\partial p}{\partial x}=-\frac{2-z}{(1+x)^{2}}<0$ and $\frac{\partial p}{\partial z}=-\frac{1}{1+x}<0$

Proof of C10. Given the equation for $L^{*}$, we simply have to prove that $\frac{\partial q}{\partial x}>0$. Consider now $\frac{\partial q}{\partial x}$ : its sign is equivalent to that of $\frac{\partial \log q}{\partial x}$, with $\log q=\frac{1}{1+x} \frac{1}{1-p} \log p$. It follows that:

$\frac{\partial \log q}{\partial x}=\frac{\partial \log q}{\partial q} \frac{\partial q}{\partial x}=\frac{1}{q} \frac{\partial q}{\partial x}=-\frac{1}{(1+x)^{2}} \frac{1}{1-p} \log p+\frac{1}{1+x} \frac{1}{(1-p)^{2}} \frac{\partial p}{\partial x} \log p+\frac{1}{1+x} \frac{1}{1-p} \frac{1}{p} \frac{\partial p}{\partial x}$

and going through computation we obtain:

$$
\frac{\partial \log q}{\partial x}=-\frac{1}{(1+x)^{2}} \frac{1}{1-p} \log p+\frac{1}{1+x} \frac{1}{(1-p)^{2}} \frac{\partial p}{\partial x} \log p+\frac{1}{1+x} \frac{1}{1-p} \frac{1}{p} \frac{\partial p}{\partial x}=-\frac{q b(p)}{(1+x)^{2}(1-p)^{2}}
$$

which, given the definition for $q, p$ and $b(p)$ is strictly positive, so that $\frac{\partial q}{\partial x}>0$ and $\frac{\partial L^{*}}{\partial x}>0$. 
Proof of C11. Given the equation for $L^{*}$ and given that $\frac{2-z}{1+x}<1$, we simply have to prove that $\frac{\partial q}{\partial z}>0$. Consider now $\frac{\partial q}{\partial z}$ : its sign is equivalent to that of $\frac{\partial \log q}{\partial z}$, with $\log q=\frac{1}{1+x} \frac{1}{1-p} \log p$.

We then have:

$\frac{\partial \log q}{\partial z}=\frac{\partial \log q}{\partial q} \frac{\partial q}{\partial z}=\frac{1}{q} \frac{\partial q}{\partial z}=-\frac{1}{1+x} \frac{\log p}{(1-p)^{2}} \frac{\partial p}{\partial z}+\frac{1}{1+x} \frac{1}{1-p} \frac{\partial p}{\partial z}=\frac{\partial p}{\partial z} \frac{1}{1+x} \frac{1}{(1-p)^{2}}\left(\log p+\frac{1-p}{p}\right)$

Given that $p<1$ strictly implies $\left(\log p+\frac{1-p}{p}\right)<0$ and that $\frac{\partial p}{\partial z}<0$, it follows that $\frac{\partial \log q}{\partial z}>0$ and thus $\frac{\partial q}{\partial z}>0$.

\section{References}

Alessie, R., Van Rooij, M., and Lusardi, A. 2011, Financial literacy and retirement preparation in the Netherlands, Journal of Pension Economics and Finance 10, 527-545.

Almenberg, J., and Säve-Söderbergh, J. 2011, Financial literacy and retirement planning in Sweden, Journal of Pension Economics and Finance 10, 585-598.

Anderson, A. 2013, Trading and under-diversification, Review of Finance, 17, 1699-1741.

Behrman, J. R., Mitchell, O. S., Soo, C. K., and Bravo, D. 2012, How Financial Literacy Affects Household Wealth Accumulation, American Economic Review 102, 300-304.

Bertaut, C. C., and Haliassos, M. 1995, Why Do So Few Hold Stocks?, Economic Journal $105,1110-1129$.

Blundell, R., Dearden, L., Meghir, C., and Sianesi, B. 1999, Human capital investment: the returns from education and training to the individual, the firm and the economy, Fiscal Studies 20, 1-23.

Blundell, R., Dearden, L., Goodman, A., and Reed, H., 2000, The Returns to Higher Education in Britain: Evidence from a British Cohort, Economic Journal 110, F82-F99. 
Board of Governors of the Federal Reserve System (US) 2016, 3-Month Treasury Bill: Secondary Market Rate [TB3MS], retrieved from FRED, Federal Reserve Bank of St. Louis; https://fred.stlouisfed.org/series/TB3MS, July 26, 2016.

Board of Governors of the Federal Reserve System (US) 2016, 10-Year Treasury Constant Maturity Rate [DGS10], retrieved from FRED, Federal Reserve Bank of St. Louis; https://fred.stlouisfed.org/series/DGS10, July 26, 2016.

Borghans, L., Golsteyn, B., Heckman, J., and Meijers, H. 2009, Gender Differences in Risk Aversion and Ambiguity Aversion, Journal of the European Economic Association 7, 649-658.

Barber, B. M., and Odean T. 2001, Boys will be boys: Gender, overconfidence, and common stock investment, Quarterly Journal of Economics 116, 261-292.

Bucher-Koenen, T., and Lusardi, A. 2011, Financial literacy and retirement planning in Germany, Journal of Pension Economics and Finance 10, 565-558.

Christiansen, C., Joensen, J.S., and Rangvid J. 2008, Are economists more likely to hold stocks?, Review of Finance 12, 465-496.

Corsini, L., and Spataro, L. 2015, Optimal decisions on pension plans in the presence of information costs and financial literacy, Journal of Public Economic Theory 17, 383414.

Croson, R. and Gneezy, U. 2009, Gender differences in preferences, Journal of Economic literature 47, 448-474.

Crossan, D., Feslier, D., and Hurnard, R. 2011, Financial literacy and retirement planning in New Zealand, Journal of Pension Economics and Finance 10, 619-635.

Crawford, M., Church, J., and Akin, B. 2016, CPI Detailed Report, Data for June 2016, Bureau of Labor Statistics. 
Dearden, L. 1999, The effects of families and ability on men's education and earnings in Britain, Labour Economics 6, 551-567.

Ehrlich, I., Hamlen W., and Yin, Y. 2008, Asset Management, Human Capital, and the Market for Risky Assets, Journal of Human Capital 2, 217-262.

Ehrlich, I., and Shin, J. 2010, Human Capital and Imperfectly Informed Financial Markets, American Economic Review 100, 244-249.

Ehrlich, I. Shin, and Yin, Y. 2011, Private Information, Human Capital, and Optimal "Home Bias” in Financial Markets, Journal of Human Capital 5, 255 - 301.

Fornero, E., and Monticone, C. 2011, Financial literacy and pension plan participation in Italy, Journal of Pension Economics and Finance 10, 547-564.

Guiso, L., and Jappelli, T. 2009, Financial literacy and portfolio diversification, CSEF Working Papers 212.

Jappelli, T. 2010, Economic Literacy: An International Comparison, Economic Journal 120, $429-451$.

Jappelli, T., and Padula, M. 2011, Investment in Financial Literacy and Saving Decisions, Journal of Banking and Finance 27, 2779-2792.

Klapper, L., and Panos, G. A. 2011, Financial literacy and retirement planning: the Russian case, Journal of Pension Economics and Finance 10, 599-618.

Lusardi, A., and Mitchell, O. S. 2011a, Financial literacy around the world: an overview, Journal of Pension Economics and Finance 10, 497-508.

Lusardi, A., and Mitchell, O.S. 2011b, Financial literacy and retirement planning in the United States, Journal of Pension Economics and Finance 10, 509-525. 
Lusardi A., Michaud, P., and Mitchell, O. S. 2011, Optimal Financial Literacy and Saving for Retirement, Working Papers 905, RAND Corporation Publications Department.

Malmendier, U., and Nagel, S. 2011,Depression babies: Do macroeconomic experiences affect risk-taking?, Quarterly Journal of Economics 126, 373-416.

Makarov, D., and Schornick, A. V. 2010, A note on wealth effect under CARA utility, Finance Research Letters 7, 170-177.

Mas-Colell, A., Whinsthon, M. D., and Green, J. R. 1995, Microeconomic Theory, Oxford University Press.

Mitchell, O. S., and Lusardi, A. 2011, Financial Literacy: Implications for Retirement Security and the Financial Marketplace, Oxford University Press, Oxford.

OECD 2014, PISA 2012 Results: Students and Money (Volume VI): Financial Literacy Skills for the 21st Century, OECD Publishing, Paris.

OECD 2016, Financial Education in Europe Trends and Recent Developments, OECD Publishing, Paris.

Powell, M., and Ansic, D. 1997, Gender differences in risk behaviour in financial decisionmaking: An experimental analysis, Journal of Economic Psychology 18, 605-628.

Renneboog, L., and Spaenjers, C. 2012, Religion, economic attitudes, and household finance, Oxford Economic Papers 64, 103-127.

Sekita, S. 2011, Financial literacy and retirement planning in Japan, Journal of Pension Economics and Finance 10, 637-656.

Thomas, A, and Spataro, L. 2015, Financial Literacy, Human Capital and Stock Market Participation in Europe: An Empirical Exercise under Endogenous Framework, Department of Economics and Management Discussion paper No. 2015/194. 
van Rooij, M., Lusardi, A., and Alessie, R. 2011, Financial literacy and stock market participation, Journal of Financial Economics 101, 449-472.

van Rooij, M., Lusardi, A., and Alessie, R. 2012, Financial Literacy, Retirement Planning and Household Wealth, Economic Journal 122, 449-478.

Varian, H. R. 1992, Microeconomic Analysis, Norton \& Company, 3rd edition, New York.

Vissing-Jorgensen, A. 2002, Limited asset market participation and the elasticity of intertemporal substitution, Journal of Political Economics 110, 825-853. 